\title{
O TRABALHO INFORMAL NA CIDADE FORTALEZA: ENTRE 0 SANEAMENTO URBANO, POLÍTICAS PÚBLICAS E A FILOSOFIA (1880-1910)
}

Daniel Camurça Correia

Doutor em História Social (PUC/SP). Mestre em História (PUC/SP). Graduação em História (UFC). Líder do Grupo de Pesquisa em Filosofia do Direito (UNIFOR). Professor das disciplinas de Filosofia do Direito e Ciência Política (UNIFOR).

\section{Resumo}

Busca-se com este artigo analisar as maneiras pelas quais os trabalhadores das ruas, tais como carregadores, vendedores e pedintes, articulavam seus dias na cidade de Fortaleza, no final do século XIX, em meio as articulaçóes políticas e normativas da província cearense. Apesar das diversas tentativas da elite política, médica e intelectual estabelecerem discursos e práticas contra a presença maciça, o trabalho desarticulado e o corpo doente dos populares, estes, cada vez mais, se faziam presentes por meio dos trabalhos realizados, seja em tempos de seca, seja no período da belle époque fortalezense. Por meio da análise das fontes, problematiza-se a tipificaçáo dos trabalhadores pobres e informais, no momento em que a elite econômica fortalezense desejava instaurar a modernidade comercial na capital cearense. Para o desenvolvimento do artigo foi realizada pesquisa bibliográfica, além do levantamento de dados da época, como fontes primárias (Relatório do Secretario Interino dos Negócios do Interior da Província do Ceará, Atas de Correspondência da Intendência Municipal da cidade de Fortaleza, Atas de Correspondência do Paço Municipal da cidade de Fortaleza); fontes secundárias (Código de Posturas da Cidade de Fortaleza); e livros de crônicas e memórias da cidade de Fortaleza.

\section{Palavras-chave}

Trabalho de rua; Filosofia; Política e higiene.

\section{Abstract}

With this papper we aim to analyze the ways in which some people as self-employed, workers of the streets, such as porters, sellers and beggars, articulated his days in the city of Fortaleza, in the end of nineteenth century, between the political and regulatory joints of Ceará province. Despite of several attempts by the political, medical and establish 
intellectual high society discourses and practices against the massive presence of this kind of sel-employed, the disjointed work and the sick body of the popular, these, increasingly, were present through the work carried out, whether in times of drought, is the period of the belle époque of Fortaleza. Through the analysis of the sources, discusses to typify poor and informal workers, at the time when the economic elite of Fortaleza wanted to establish commercial modernity in this city. For the development of this article, we used literature and bibliographical research. Was performed in addition to the survey data of the time as another primary sources (Acting Secretary of the Business of Interior of Ceará Province Report, Match Proceedings of the Municipal Stewardship of Fortaleza, Correspondence Minutes of city Hall of Fortaleza); and secondary sources (Postures Code of the City of Fortaleza); and chronic books and besides memories of the city of Fortaleza.

\section{Key words}

Street work; Philosophy; Politics and hygiene.

\section{Introdução}

Os Relatórios dos Presidentes da Província do Ceará, no decorrer dos anos da recente República brasileira, afirmavam que à medida que se aproximava o final dos oitocentos, Fortaleza estabelecia-se enquanto centro urbano, o que também significava que seus problemas citadinos se tornavam visíveis. As epidemias eram constantes, atingindo principalmente a população pobre, na qual, muitos residiam debaixo de árvores ou nos arrabaldes. O Dr. João Marinho de Andrade, responsável pela higiene pública da capital cearense, reclamava do ininterrupto aumento da população, pelo fato dela ser desorganizada e geradora de males diversos ${ }^{1}$.

Em 1893, o Dr João Marinho havia avisado que

O nosso serviço de vaccinação é defficiente e imperfeito visto como havemos lympha vaccinica da capital federal ou do exterior, e esta que nos é remettida nem sempre é proveitosa, si bem que venha com o cunho de garantida e excellente ${ }^{2}$.

O governo provinciano, então, não tinha condições de organizar o cuidado dos corpos e da saúde. Mesmo que se organizassem para ter pessoas e estrutura, os equipamentos

1 (Biblioteca Pública Menezes Pimentel- setor de microfilmagem) Relatorio que o Secretario Interino dos Negocios do Interior Bacharel Thomas Pompeu Accioly apresenta ao Exm Sr. Presidente do Estado, 1894, P. 71.

2 (BPMP-setor de microfilmagem) Relatorio que o Secretario Interino dos Negocios do Interior, Antonio Salles apresenta ao Exm Sr. Presidente do Estado, 1893, P. 37. 
não atendiam as expectativas, pois não suportavam o transporte até as províncias do norte (oriundas do Rio de Janeiro). As condições apresentadas pela Secretaria Interina dos Negócios do Interior demonstravam que a população não era inoculada, proliferando as doenças na região.

Segundo o médico citado acima, $40 \%$ da população, entre crianças e adultos, ainda não tinham sido vacinados. $\mathrm{O}$ serviço de higiene pública não tinha estrutura alguma para montar um Sistema de Vacinação sobre a cidade. Na verdade, a Inspetoria de Higiene não tinha sequer um prédio para realizar suas atividades ${ }^{3}$.

Ainda piorava a situação para o Dr. João Marinho o fato da população se negar a ser vacinada. Afirmava o médico:

Nestas condiçóes, sujeitos a tentativas experimentaes, somos forçados a aproveitar como o maior escrupulo a lympha humana reproductiva, estabelecendo a vaccinação de braço a braço, e com que dificuldades e embaraços lutamos para bem applical-a e melhor colhel-a, tal é repugnancia dos poucos que a isto se prestam $!^{4}$

Mostrando que muito do discurso articulado por aquela elite política e intelectual não se tornava prática.

Ao arrolar os Relatórios dos Presidentes da Província do Ceará, nos oitocentos, percebe-se ampla discussão acerca da organização da higiene urbana. Para entender as ações cotidianas dos trabalhadores das ruas (informais) é necessário entender o que enfrentavam diariamente. No caso, em primeira instância, o modo como era pensado e articulado à salubridade de Fortaleza; a maneira como os médicos olhavam para a cidade; como a população agia diante da disciplinarização do corpo e do espaço em meio à realizaçáo de seus trabalhos. (FOUCAULT, 2011)

O objetivo desta pesquisa é analisar a forma como a população pobre e trabalhadora informal, na cidade de Fortaleza, no final do século XIX, vivia, trabalhava e se relacionava com os dispositivos normativos (políticos, filosóficos, econômicos e higiênicos). O papel da recente República, naquele momento, era intensificar o discurso da centralização do poder. Por outro lado, não conseguir estabelecer os mecanismos necessários para o funcionamento da coisa pública.

Era objetivo do poder público cearense manter a assepsia dos espaços e dos corpos. As ruas deveriam permanecer limpas; os produtos alimentícios deveriam ter boa procedência, para tal, seria fiscalizado pela Intendência Municipal; os trabalhadores obedeceriam aos

3 (BPMP-setor de microfilmagem) Relatorio que o Secretario Interino dos Negocios do Interior Bacharel Thomas Pompeu Accioly apresenta ao Exm Sr. Presidente do Estado, 1895, P. 66.

4 (BPMP-setor de microfilmagem) Relatorio, 1894. Op. Cit., P. 71. 
preceitos médicos no espaço público; tudo isto respeitando as Posturas Municipais da época. Sobre estas questóes afirma Sebastiāo Ponte, no livro Fortaleza belle époque:

Se tais prescriçốes foram ou não de fato cumpridas, é difícil saber. Entretanto, importa perceber que estas determinaçóes municipais desvelam a vigência de um saber que cada vez mais vigia a cidade e povo em seus menores detalhes. Denotando imensa vontade de desodorizar o espaço urbano e modificar hábitos da população, aqueles enunciados certamente acabavam por produzir efeitos de verdade e de poder que foram operando, mesmo que fragmentariamente codificaçôes reguladoras no interior da relação recíproca habitante-cidade (PONTE, 1993, 81).

Fortaleza, para Ponte, ganhava junto com o crescimento urbano a disciplina e controle sobre a população. Novos costumes foram implementados em detrimento dos antigos, considerados, agora, nocivos à saúde e ao bem comum. Era a "modernização" batendo na porta dos fortalezenses.

Sebastiāo Ponte discute as reformas urbanas ocorridas na capital cearense no período de 1860 até 1930, apontando transformações que representavam o "aformoseamento" da cidade e a incessante luta que a elite política travava contra a população pobre para tornar a cidade "civilizada" através da disciplina dos corpos.

O livro de Sebastião Ponte aponta alguns trabalhadores das ruas, descrevendo um pouco de seus "misteres", levantando o véu que esconde o universo dos trabalhadores informais da cidade de Fortaleza, dialogando o papel destes diante do discurso de médicos e sanitaristas, os quais aplicavam seus olhares sobre as trajetórias dos carregadores e vendedores ambulantes na capital cearense (PONTE, 1993, 56).

Avançando o olhar sobre outras fontes foi percebido, entretanto, que a "modernização" de Fortaleza não alcançava, muitas vezes, a todos os espaços da cidade. Nos arrabaldes, por exemplo, o controle sanitário não tinha sido implantado. De acordo com as Atas da Câmara Municipal de Fortaleza, os fiscais não conseguiam impor a ordem no Matadouro Público.

Os fiscais do Matadouro Público tentavam impedir que o gado vacum fosse abatido fora do local determinado, bem como vendido longe do mercado municipal ou dos açougues licenciados. Todavia, os populares impediam que os fiscais cumprissem suas obrigaçóes. O intendente se via obrigado a pedir a presença dos guardas cívicos no local para protegerem os fiscais ${ }^{5}$. No que diz respeito à área relativa à "circunscripção urbana" a situação não era muito diferente. Os fiscais não conseguiam cumprir as normas:

5 (Arquivo Público do Estado do Ceará) Atas de Correspondência. Intendencia Municipal, Fortaleza, 25 de setembro de 1906, n 788 . 
Por toda a cidade, com violação patente da lei municipal, por cujo cumprimento cabe tambem velar a força publica, a cada passo se encontra mercadores ambulantes de carne de gado, sem que tinham satisfeito as exigencias legaes, procurando ao contrario subtrahirem-se á acção fiscal com o emprego de meios violentos que por seu termo reclamam a coação da força publica (THEOPHILO, 1997, 21).

Com a pesquisa, surgiu uma série de indícios sobre trabalhadores pobres e livres na capital cearense. Eram em sua maioria trabalhadores das ruas, os quais não tinham local fixo de trabalho. Ora estavam nas ruas, se colocavam nas praças, dirigiam-se para o Matadouro Público, estavam nas feiras, desciam a rampa da Santa Casa de Misericórdia, ou mesmo prestavam pequenos serviços para as residências, nas ruas principais de Fortaleza.

Os trabalhadores das ruas, em sua maioria, não praticavam apenas um "mister", isto era relativo às necessidades urbanas e a forma como percebiam estas necessidades. Em momentos de seca e epidemias, muitos se tornavam carregadores de cadáveres, empregando-se temporariamente na Santa Casa. Pelas dificuldades que Fortaleza passava no período de seca, os poderes públicos se viam a mercê dos trabalhadores ambulantes, que determinavam o próprio preço e a hora de trabalho, pois a Câmara Municipal não tinha meios para concretizar o controle sobre este comércio (THEOPHILO, 1997, 21).

Em períodos de abundância, os ambulantes dividiam-se em diversos afazeres, muitos se tornavam vendedores de carne verde (carne fresca), aguadeiros, vendedores de frutas, acrobatas e "quimoeiros" . Outros eram pedintes, batendo nas portas das casas mostrando as chagas deixadas pela varíola.

A leitura das fontes provinciais do período republicano suscitou várias indagaçôes, tornando o assunto complexo e interessante: Quem eram estes trabalhadores das ruas? Como realizavam seus "misteres" numa cidade que a elite política e intelectual queria limpa e controlada? Como pensar em trabalho informal num momento que se desenvolvia na capital cearense um mercado forte, homogêneo e formal, transformando-a em hegemônica diante de outras cidades cearenses? Como estes trabalhadores se relacionavam com seus fregueses?

Desta forma, para o desenvolvimento metodológico do referido artigo foi utilizada a pesquisa bibliográfica, além do levantamento de dados da época, por meio da leitura e análise das fontes primárias (Relatório do Secretario Interino dos Negócios do Interior da Província do Ceará, Atas de Correspondência da Intendência Municipal da cidade de Fortaleza, Atas de Correspondência do Paço Municipal da cidade de Fortaleza); fontes secundárias (Código de Posturas da Cidade de Fortaleza); e livros de crônicas e memórias da cidade de Fortaleza.

6 Termo designado para aqueles que transportavam o quimo - resultado do quilo (alimento digerido). 


\section{Fortaleza entre 0 Trabalho Informal e a Política}

O livro A multidão e a história, de Frederico de Castro Neves, estuda os movimentos de massas organizados pelos retirantes, os quais buscavam abrigo junto ao Estado nos momentos de seca, entendendo o significado do saque como uma manifestação política, organizada e gerenciada pelos retirantes, quando acreditavam que o poder público deveria assegurar-lhes a sobrevivência durante as secas, substituindo as práticas da "caridade pública” (NEVES, 2000, 50).

Pela necessidade em problematizar os diversos vestígios deixados pela documentação, uma análise sobre a discussão de cidade em muito acrescentaria o debate sobre o cotidiano dos trabalhadores das ruas, permitindo compreender a complexa teia das relaçóes sociais na qual estes sujeitos estavam inseridos. Entender a tensa relação entre trabalho popular e política não é novidade, na história, nem na filosofia do direito. Os estudos sobre Sócrates apontam suas discussóes acerca de como as elites políticas desacreditavam os populares, ou o saber popular (BITTAR; ALMEIDA, 2011, 99)

Atualmente existem pesquisas que problematizam a construção da seca enquanto pano de fundo para a compreensão dos movimentos sociais no nordeste brasileiro. Alguns estudiosos afirmam que a seca se torna o motivo único e indiscutível sobre a pobreza rural no semiárido. Diante desta afirmativa desaparece a possibilidade de observar a organização social fortalezense, em período de seca, como um campo permeado por conflitos entre as diferentes categorias sociais, no qual a seca vem no intuito de criar argumentos que favoreçam interesses específicos (NEVES, 2000, 15).

Ao se reafirmar o poder da seca diante dos homens, tem-se como consequência a fome, que leva as pessoas a cometerem as maiores atrocidades. Com este argumento fica claro que o homem se torna um mero instrumento de seu organismo, que, desesperado, perde o controle de sua mente, sendo obrigado a matar suas necessidades vitais, a qualquer custo.

Um destes custos poderiam ser os "degradantes" trabalhos das ruas, que de acordo com o discurso sanitário, deveria ser abolido dos centros urbanos. Mas não foram, porque existiam pessoas, que, levadas pela fome e pela "loucura", precisavam sobreviver, realizando estes "misteres".

A questão é exatamente a visibilidade que a seca ganha dentro dos centros urbanos. Mais do que a falta d'água, a seca trouxe um exorbitante número de "emmigrantes" para dentro de Fortaleza, a qual não esperava tamanha "invasão". E aí se constituiu o maior problema das famílias abastadas de Fortaleza: receber os "esfaimados e andrajosos" num momento em que a cidade estava começando a sentir o gosto da "aventura civilizatória". Ou seja, a seca, por si só, não se constitui enquanto problema social, afinal de contas, 
Em termos de intensidade, duração, extensão ou mortalidade, no entanto, a seca de 1877 não se diferencia tanto de outros períodos de escassez, nem mesmo em termos de prejuízos econômicos (NEVES, 2000, 15).

Por conta destes deslocamentos realizados pelos moradores do interior do Ceará, foi possível compreender a visibilidade que os responsáveis pela organização pública passaram a ter. Porém, era legítimo para aquelas pessoas que o apoio, a proteção deveria ser fornecida pela força imperial, então, a saída seria se dirigir ao centro deste poder - no caso, a sede da província (NEVES, 2000, 42).

Ao mesmo tempo, devido a esta mobilidade crescente da população camponesa em busca da proteção estatal no espaço público da cidade, os períodos de escassez transformam-se em um problema social que afeta o conjunto da sociedade cearense e, portanto, ganha visibilidade social e espaço nas políticas oficiais. Assim, diante desse quadro, a seca de 1877 se apresenta como de gravíssimas proporçóes, fechando o ciclo dos períodos de escassez em que apenas se contabilizavam as perdas, se conjeturavam quanto às razóes da irregularidade de chuvas e se lamentavam as mortes - a seca torna-se, a partir de então, um 'fenômeno social'(NEVES, 2000, 47).

Durante a seca, muitos já estavam prestando algum tipo de serviço. Foram os próprios retirantes os responsáveis por levar os mortos por varíola para suas covas, trazendo também medo e repugnância para os moradores da cidade.

Quantas vezes as familias chegando as janelas de suas casas, entravam horrorisadas porque deparavam com estes esquifes estendidos nas calçadas e ao lado os carregadores que excitados pelo alcool, descansavam da carga palrando sem sem descanso (THEOPHILO, 1997, 13).

$\mathrm{Na}$ medida em que os anos passavam, foram construídos por parte das autoridades públicas e sanitárias longos discursos em nome da "moral", da "saúde" e da "família" contra a prática "nociva" dos trabalhadores das ruas. Discursos estes que buscavam controlar, racionalizar e desinfetar os costumes de carregadores e vendedores ambulantes.

Em 1913, de acordo com o Código de Posturas, estes trabalhadores já não deveriam existir mais. Para o Presidente da Câmara, José Brasil de Mattos, para vender carne verde, por exemplo, era necessário ter

Attestado da autoridade ou de dois cidadáos qualificados do districto de sua reidencia, que abonem a sua conducta e attestado medico para provar que não estava doente por moléstias cutâneas ou contagiosas?.

7 CÓdigO DE POSTURAS DE FORTALEZA. Fortaleza: Typ. Minerva, 1916, P. 13. 
Ou seja, a partir da década de 1910, colocava-se em prática meios para que os trabalhadores das ruas fossem numerados e matriculados na Intendência Municipal. Os carregadores de cadáveres foram um dos primeiros, pois "na era do automóvel [depois de 1913] os corpos deveriam ser levados 'por veículos a motor”" (MENEZES, 1938, 43).

$\mathrm{O}$ que não quer dizer, necessariamente, que os trabalhadores das ruas tenham desaparecido de Fortaleza. Pelo contrário, como antes, estes trabalhadores se adequaram - e ainda se adequam - as novas realidades vigentes. Como estavam entre um trabalho e outro, suprimindo um, sempre existia outro para fazer. Muitas vezes prestavam serviços domésticos, ou mesmo esmolavam pelas ruas.

No final da década de trinta, ainda existiam “antigos 'gatos pingados': João Cavalo, trabalhador de rua, Antonio Coelho, empregado na capatazia da alfandega, e o trabalhador de rua que atende pela alcunha de 'capitão"' (MENEZES, 1938, 43).

A partir da década de 1910, outro momento ficou marcante, no qual as estratégias articuladas pelos poderes públicos ganhavam novas formas. Mas, por outro lado, também ganhava forma às táticas de resistências, a maleabilidade para fugir ou utilizar da nova realidade, mostrando a possibilidade de descortinar fragmentos do passado para compreender-se "modos de vida" de sujeitos que, de forma alguma, estavam fora daquela sociedade.

Para nortear as discussóes referentes às categorias de análises aqui dispostas, é imprescindível a leitura de alguns historiadores que já problematizaram o universo do trabalho urbano no final do século XIX. Muito se tem produzido na historiografia destes últimos anos sobre a questão da pobreza urbana, apresentando, dentro de suas especificidades, os mecanismos aplicados pelos poderes públicos sobre a população pobre, ao mesmo passo que se tenta discutir as táticas de resistências destes que burlavam e contornavam autoridades políticas e sanitárias, fazendo e refazendo seus espaços de sobrevivência. Por esta razão, torna-se imprescindível uma análise sobre autores que auxiliam no estudo dos trabalhadores informais, construindo um diálogo, realizando apropriações de leituras e metodologias.

Dos trabalhos realizados sobre Fortaleza, no século XX, surgem diferentes leituras sobre as classes pobres e suas formas de organizaçáo. A dissertaçáo de mestrado de Kênia Sousa Rios, Isolamento e poder, está permeada por discussóes sobre o isolamento em Fortaleza, na seca de 1932, compreendendo os mecanismos de controle sobre os flagelados pelos poderes urbanos, na intenção de legitimar o discurso sobre a necessidade destes campos.

A partir de alguns problemas levantados por Kênia Rios, sobre a população pobre de Fortaleza, a qual adentrava mais e mais na capital cearense, "preocupando" e "assustando" autoridades médicas e sanitárias, se quer refletir os trabalhadores informais, que representam, neste texto, uma parcela significativa da população pobre que fugia e se escondia 
dos olhares higienizadores, ao mesmo tempo em que viviam e trabalhavam nos principais boulevards (RIOS, 1998).

Com o trabalho de Maria Auxiliadora Lemenhe, As razóes de uma cidade, no qual ela faz um estudo sobre o fenômeno da construção da cidade de Fortaleza enquanto polo econômico dos oitocentos demonstra o crescimento da capital do estado na perspectiva da "cidade-empório", estudando a hegemonia que a urbe passou a ter, principalmente depois da independência do Brasil, graças à exportação do algodão e a sistematização do império em organizar administrativamente a sede do poder cearense (LEMENHE, 1991, 18).

O livro de Auxiliadora Lemenhe observa o crescimento e a estruturação do mercado no Brasil, em geral, e o de Fortaleza, em particular, mostrando a força que o "capitalismo mercantil" tinha, exigindo uma maior disciplinarização do trabalho. Com isso, surge o espaço para o diálogo com as teias do comércio paralelo de, por exemplo, aguadeiros e vendedores ambulantes de carne, frutas e doces, tentando entender como os trabalhadores informais executavam suas tarefas em uma cidade que cada vez mais era sistematizada e organizada pelo mercado externo.

O trabalho de Marta Emísia Barbosa, Cidade na contramão, faz um estudo sobre os mecanismos de controle dos poderes públicos para disciplinarem - a partir do discurso da moral - a população pobre e seus comportamentos em Fortaleza, nas primeiras décadas do século XX. O diálogo com Marta Emísia é construído no intuito de compreender a teia de relaçóes sociais das classes menos favorecidas, percebidas através das documentaçóes analisadas pela autora, como: processos crimes, livros de queixas, rol de culpados e relatórios de polícia, as quais são ricas em indícios do dia a dia da população pobre, seus conflitos com guardas, com outros vendedores e com o saber médico, demonstrando que a moral era um norte para coagir práticas consideradas pelas autoridades médicas e policiais como "desviantes" (BARBOSA, 1996).

Ao construir o diálogo com trabalhos que analisam as especificidades do cotidiano da pobreza urbana em outras metrópoles brasileiras, surge a oportunidade em estabelecer uma discussão com Maria Odila Leite da Silva Dias, no livro Quotidiano e poder, o qual, como afirma a própria historiadora sobre seu trabalho

É uma contribuição para o conhecimento dos papéis histórico de mulheres das classes oprimidas, livres, escravas, e forras, no processo de urbanizaçáo incipiente da cidade de São Paulo, entre fins do século XVII e as vésperas da abolição; não me refiro a papéis sociais normativos e prescritos, mas as mediaçóes sociais continuamente improvisados no processo global de tensôes e conflitos, que compóem a organização das relações de produção, o sistema de dominação e de estruturação do poder (DIAS, 1984, 07). 
Dias abre espaço, principalmente, para duas questóes referentes ao tema aqui proposto: primeiro, o fato da autora adentrar no universo do trabalho informal compreendendo uma estrutura social, na qual fica em destaque o papel da mulher pobre, livre ou escrava, realizando diversos "misteres" na cidade de São Paulo, no decorrer do século XIX.

Essa leitura, trazida para as especificidades espaço temporais de Fortaleza, em fins do século XIX, discute o fato da documentação pouco indicar as mulheres trabalhando e sobrevivendo nas ruas. Percebe-se assim, que não deve ser estudada com naturalidade a construção do trabalho como papel exclusivo de homens. Surge, neste momento, uma indagação: no caso da capital cearense, no final dos oitocentos, não existiram mulheres realizando trabalhos informais, ou não registraram as mulheres vendendo carne verde ou mesmo carregando cadáveres ou barris de quimoas?

A segunda questão seria o próprio fato de Dias reconhecer estas mulheres como trabalhadoras, pessoas que criavam e recriavam as práticas e formas de convivência de seus dias, em casa ou no trabalho. Pois, nas pesquisas que, geralmente, fazem apenas algumas citações sobre os carregadores e vendedores ambulantes em Fortaleza não são dados àquelas pessoas o tratamento de trabalhadores, mesmo que a documentação permita esta compreensão.

Para alguns historiadores do Ceará transparece a ideia que a informalidade de alguns trabalhos deva ser considerada muito mais "transgressão" do que "trabalho". Para este artigo não deve ser desconsiderado o caráter de transgressáo dos "misteres", pois as autoridades públicas criavam leis muito severas frente aos vendedores e carregadores ambulantes. Porém, como problematiza a historiadora, aqueles homens e mulheres criavam modos de viver que em muito ultrapassa o simples conceito de "transgressão", pois suas análises enfocam uma realidade complexa e muito bem organizada por sujeitos construtores da história de seus dias.

Mas, a perspectiva retratada por Maria Odila Dias (1984) precisa ser enfatizada, pelo fato de se entender as práticas dos trabalhadores das ruas como algo muito mais abrangente do que os conceitos construídos pelas autoridades políticas fortalezenses.

Se se estudar a elaboração deste discurso disciplinador, enfocando outras documentaçôes das quais transparecem a visão dos trabalhadores informais como realizadores de pequenos ofícios vem à tona a possibilidade de analisar as tessituras de um cotidiano multifacetado em discursos e práticas diversas, trazendo à luz elementos constitutivos da sociedade, política e economia fortalezense.

\section{Políticas Públicas e o Espaço Urbano}

Documentos oficiais, como Atas de Correspondência da cidade de Fortaleza ajudaram a problematizar os embates entre os trabalhadores das ruas e os guardas fiscais e 
municipais da Intendência, apontando momentos em que a lei era estabelecida ou não. Ao mesmo passo, tenta-se compreender de que maneiras os guardas, fiscais e soldados do exército interagiam com a cidade para a manutenção ou quebra da ordem e do sossego público.

Ao observar as atitudes e posturas de guardas e fiscais nas ruas, para compreender a política que estavam tentando implantar, considerou-se pertinente o levantamento dos Códigos de Posturas da Câmara Municipal, da década de 1910, existente na Biblioteca Dolor Barreiro, porque é entendido que os guardas da Câmara eram os representantes do poder público nas ruas.

O referido código faz-se importante por legitimar o controle destes policiais, dando-lhes poderes para agirem sobre a população pobre, buscando o modo pelo qual a Intendência da capital cearense legitimava o discurso de controle e coerção sobre os trabalhadores das ruas, através das leis e suas respectivas puniçóes.

Adentrando nos textos dos Relatórios (1889-1915) - microfilmes pertencentes à Biblioteca pública Menezes Pimentel - ficou perceptível que, quanto mais era valorizada a necessidade em aformosear a capital cearense, mais era importante esconder as marcas do “atraso" daquela cidade. Assim, para os presidentes do estado do Ceará, os carregadores e vendedores ambulantes espalhados por toda a cidade simbolizavam as marcas da "sujeira", do "atraso", do "feio" e da "doença".

Com o exame de algumas obras de época, foi possível analisar a imagem construída, por memorialistas, dos trabalhadores das ruas a partir do epíteto depreciativo do "tipo popular”. Otacílio de Azevedo, memorialista que chega à cidade de Fortaleza em 1910, vindo de Redenção - interior do Ceará, escreveu em seu livro Fortaleza descalça; reminiscências sobre os quimoeiros de Fortaleza, tecendo seu juízo de valor sobre a aparência e os “tristes misteres" que realizavam (AZEVEDO, 1980).

Ao escrever sobre os carregadores de quimoa, o memorialista insere esse assunto no capítulo intitulado $A$ Cidade e as lembranças. Primeiramente, Otacílio de Azevedo separa o quimoeiro Pisa Macio da imagem do "tipo popular", dando a entender que sua visão convergia na associação entre quimoeiro e trabalhador. Todavia, ao analisar a sua descrição com o artigo seguinte, Tipos curiosos, encontra-se Tostão, outro quimoeiro. Neste momento, Azevedo não dedica suas linhas ao "mister", mas ao jeito de ser, esmolar e chamar a atenção.

O que ocorre é que a imagem que os quimoeiros tinham - a de um trabalhador passa a ser a imagem de um "louco", pela necessidade de retirar aquela prática das ruas e pelo fato de ter nas ruas da capital da província alguém que realizasse o ofício de carregar barris com materiais fecais. 
Ou seja, o autor descaracteriza a condição do trabalho. Demonstra dificuldades de entender, ou aceitar, que o trabalho de rua, informal, de alguma maneira está atrelado ao desenvolvimento da economia local. Pelo fato das autoridade tentarem, a todo custo, garantir a assepsia da cidade, o autor trata de menosprezar os trabalhadores, e não o aviltante trabalho exercido pelos quimoeiros.

Rodolpho Theophilo, farmacêutico e higienista que, de 1900 até 1904, imunizou - sem apoio do Estado - parte considerável da população de Fortaleza contra a varíola, escreveu Varíola e vacinação no Ceará. Em seu trabalho o autor lançou um olhar higienista sobre os carregadores de cadáveres de variolosos durante a seca, informando o quanto era degradante para os moradores assistir o transporte dos mortos. Theophilo associou aos trabalhadores das ruas a imagem do "sujo" e do "atraso" por causa da maneira que estes homens realizavam seus ofícios, em meio a um período de epidemia (THEOPHILO, 1997).

Por outro lado, mesmo com os comentários carregados de preconceitos e estereótipos sobre os trabalhadores informais, o autor revela particularidades, bem como saberes sobre o transporte e enterramento dos defuntos, apresentando, muitas vezes, que os carregadores não recebiam nenhum tipo de apoio - nem financeiro, nem material - para executarem o "mister", revelando os saberes que aquelas pessoas utilizavam para concluírem o serviço, suas poçôes e remédios caseiros, seus líquidos para amenizar dores, odores e doenças.

O cronista Raimundo de Menezes, no trabalho intitulado Coisas que o tempo levou... (crônicas históricas da Fortaleza antiga), também faz o mesmo que Otacílio de Azevedo. A diferença é que Menezes enfatiza seu discurso sobre os "gatos pingados". Ambos retratam momentos importantes para este texto, não somente por destacarem o "mister" dos trabalhadores informais, mas por deixarem claro a relação entre estes trabalhadores, o risível e o "atraso", demonstrando que a piada, escrita pelos memorialistas serviria muito mais para moralizar os trabalhadores e aqueles que liam as crônicas, do que revelar particularidades engraçadas e despretensiosas sobre a memória fortalezense (MENEZES, 1938).

Já Gustavo Barroso, no livro Memórias de Gustavo Barroso, segue outros caminhos - escrito em 1939, intitulando o capítulo que descreve acerca dos quimoeiros da cidade de Fortaleza de Tipos de rua. Sendo que, a maior parte de texto escreve sobre a vida de Romão ${ }^{8}$, sua família, sua alimentação e o seu "triste fim” (BARROSO, 1989).

$\mathrm{O}$ autor diferencia-se também por demonstrar o conflito entre policiais que agrediram e prenderam Sabão Mole - outro quimoeiro - deixando visível a rede de conflitos

8 Um quimoeiro, ex-escravo, casado, com filhas, que perambulava pelas ruas de Fortaleza, oferendo seus serviços aos diferentes residentes da capital cearense. 
que permeavam o dia a dia dos trabalhadores comuns. De modo geral, os memorialistas de Fortaleza citam algumas passagens dos carregadores e vendedores ambulantes nas ruas do centro da cidade, transmitindo junto com as notícias sobre aqueles homens e mulheres o sentimento de compaixão e caridade.

Ao analisar o estereótipo do "tipo popular" e as imagens construídas ao redor dos trabalhadores das ruas, percebem-se mudanças significativas nos valores sociais que são impostos pelo Estado, resultando na visibilidade que este órgão dá aos trabalhadores informais, descrevendo e criticando a presença daqueles em seus documentos.

Em um período anterior a seca de 1877-79 os trabalhadores informais não pareciam ser um problema significativo para os poderes públicos, nem mesmo os costumes mais corriqueiros tinham-se transformado em problema de higiene. Em um primeiro momento, era comum na cidade de Fortaleza levar o cadáver em uma rede até a Igreja, carregar águas em canecos, despejar as imundícies nas ruas ou na praia. Depois da seca de 1877 , leis surgiram no intuito de proibir o "desfile" dos trabalhadores informais pelas ruas principais do centro.

Para compreender a dinâmica do trabalho das ruas, dentro da perspectiva cultural, política e econômica, foi necessário recuar no tempo. Ao chegar à seca de 1877-79 novos indícios apareceram. O que mais chamava a atenção do intendente - com relação à limpeza da cidade - era o lixo espalhado:

Cumpre declarar a V. Ex. que forão dadas as ordens convenientes para serem removidos os esterquilinos(sic) existemtes (...) bem como se tomarão desde logo as medidas convenientes para que não se repita o abuso de amontoar lixo e entulhos em outros logares que não sejam os designados por esta municipalidade?

Pedia-se, de acordo com o documento, a urgência em colocar sentinelas nos locais mais sujos para impedir a proliferação do lixo. Todavia, o discurso não se direcionava a um grupo específico. Eram sempre "a população" os responsáveis pela sujeira na cidade.

Com a vinda da seca, Fortaleza sofreu súbitas transformaçôes. De acordo com Frederico Neves:

A 'grande seca' de 1877 - ou a 'seca-tipo', como preferia Rodolpho Theophilo, seu grande cronista - trouxe a presença impactante de multidóes de retirantes, esfaimados e andrajosos a implorar por ajuda, 'contaminando' a cidade com sua miséria explícita, suas doenças, seus 'vícios', sua fome, seus crimes e sua ofensiva ameaça à civilização. A vida urbana passa a ser o cenário privilegiado do drama da seca (NEVES, 2000, 25).

9 (APEC) Ata de Correspondência. Paço da Camara Municipal da Cidade da Fortaleza, em Sessão Ordinaria de 21 de julho de $1871, n^{\circ} 21$. 
As pessoas, naquele momento, passavam a ser o problema. A população da cidade cresceu substancialmente. $\mathrm{O}$ que incomodava as elites políticas, sanitárias e intelectuais não era apenas a chegada dos retirantes - o que foi o suficiente para o caos na cidade - mas a chegada de uma leva maciça de pessoas, doentes, famintas e desesperadas por socorro. Pessoas que se alojavam embaixo de árvores, nas praças, encostados nos edifícios, na Santa Casa e nas Igrejas. De várias maneiras o poder público tentava dar moradia e trabalho, mas que não chegava a ser o suficiente. Muitos acabaram por se dirigirem para as periferias, construindo suas casas e ali residindo enquanto realizavam na cidade diversos trabalhos, durante o dia e a noite.

\section{Conclusões}

Desde 1877 e por anos a fio, Fortaleza viu de perto a morte, a miséria e o medo. Os fortalezenses tiveram de conviver com uma presença mais ostensiva do grupo social: os trabalhadores das ruas, espalhados por toda a cidade, dentro e fora da circunscrição urbana. Entretanto, nem só de medo viviam os moradores de Fortaleza (CAMINHA, 1973).

Se trabalhadores das ruas batiam de porta em porta, isto significava dizer que eles estavam ali, convivendo com a população. Os trabalhadores das ruas vendiam os produtos alimentícios nas praças, gritando seus pregóes; estavam em frente ao banco Gentil, com seus tabuleiros, vendendo quitutes; realizavam pequenos serviços domésticos; levavam seus mortos até o cemitério - sempre pela rua das flores.

Com os indícios apresentados pelas fontes documentais, é possível delinear uma cartografia da cidade que permite ter uma noção por onde, como e quando os trabalhadores informais utilizavam a cidade. Compreender as formas pelas quais ocorriam os confrontos com a guarda municipal, em embates - físicos, muitas vezes - demonstra que a lei não era obedecida.

Os vendedores de carne verde, por exemplo, não passavam seus produtos pela inspeção dos médicos da Intendência (medida exigida pelo Código de Postura), o que acarretava a baixa do preço. Desta forma, os preços da carne verde vendida nos açougues, dentro do Mercado Público, eram sempre mais caros, obrigando parte considerável da população comprar com os vendedores de porta em porta.

Por último, os trabalhadores eram tidos como motivo de risos e brincadeiras por parte da população, isto significa dizer que este espaço é propício para a construção do estereótipo do "tipo popular", destacado como imagem do risível e do negativo. A imagem do "tipo" ganha duas faces em uma mesma moeda: a irreverência do seu jeito de vestir e falar e as marcas da pobreza e da loucura. Deste modo, surge a oportunidade de problematizar as formas pelas quais os trabalhadores de ruas burlavam as normas e enganavam seus adversários sem perder seus fregueses e ouvintes. 
Segundo a documentação utilizada, principalmente através dos memorialistas, é perceptível toda uma articulação de homens e mulheres que, através do riso e da piada, conquistavam sua clientela. Por outro lado, náo é descartada a análise sobre as caricaturas descritas pelos cronistas sobre estes trabalhadores. Discute-se o papel destas imagens construídas dentro de uma sociedade que estreitava a relação entre pobreza, doença e loucura, no intuito de edificar o estereotipo do antimodelo de cidadão fortalezense. $\mathrm{O}$ papel do pensamento filosófico é compreender os significados político e normativo do riso, do escarnio e da caricatura sobre o outro (BERGSON, 1987).

Enfim, observou-se neste texto "aspectos informais do nosso passado" (PINTO, 1994, 07), a movimentação das ruas, o vaivém de carregadores e vendedores ambulantes na cidade de Fortaleza, tenta-se compreender as táticas de sobrevivência de trabalhadores informais que estavam constantemente vigiados pela elite política e sanitária da capital cearense, elaborando posturas municipais e articulando o papel de guardas e fiscais para a implantação da ordem e do sossego público, o que em dados momentos aconteciam e em outros não.

Concomitante a isso, compreender os costumes existentes na cidade de Fortaleza relacionado à limpeza das ruas, ao enterro de seus mortos, a elaboração das leis citadinas e a rede informal de venda e trocas de produtos alimentícios, bem como refletir estes costumes frente aos novos valores que foram trazidos para a capital cearense, ditando novos costumes e maneiras de tratamento do corpo e do trabalho, tidas pelas autoridades e pelas elites de Fortaleza como práticas "feias" e "risíveis", se faz necessário. Não apenas para entender o passado. Mas, principalmente, para entender o motivo das estruturas políticas, que também são ideológicas, em quererem, substancialmente, legislar o corpo e a mente.

\section{Referências}

AZEVEDO, Otacílio de. Fortaleza descalça; reminiscências. Fortaleza: Ediçóes UFC/ PMF, 1980. (Col. José de Alencar, 3)

BARBOSA, Marta Emisia Jacinto. Cidade na contramão: Fortaleza nas primeiras décadas do século XX. Dissertação de Mestrado: PUC/SP, 1996.

BARROSO, Gustavo. Memórias de Gustavo Barroso. Fortaleza: Governo do Estado do Ceará, 1989.

BERGSON, Henri. O riso; ensaio sobre a significação do cômico. $2^{\text {a }}$ ed. Rio de Janeiro: Editora Guanabara, 1987.

BITTAR, Eduardo; ALMEIDA, Guilherme Assis de. Curso de Filosofia do Direito. São Paulo: Atlas, 2011. 
CAMINHA, Adolfo. A normalista. São Paulo: Três Editoras, 1973 (Col. Obras Imortais de Nossa Literatura, 9).

DIAS, Maria Odila Leite da Silva. Quotidiano e poder. São Paulo: Brasiliense, 1984.

VEIGA-NETO, Alfredo. Foucault - Filosofia e politica. Rio de Janeiro: Autêntica, 2011.

LEMENHE, Maria Auxiliadora. As razóes de uma cidade: Conflito de hegemonias. Fortaleza: Stylus Comunicaçôes, 1991.

MENEZES, Raimundo de. Coisas que o tempo levou... (Crônicas históricas da Fortaleza antiga). Fortaleza: Edésio Editor, 1938.

NEVES, Frederico de Castro. A multidão e a história: saques e outras açóes de massas no Ceará. Rio de Janeiro: Relume Dumará, 2000.

PINTO, Maria Inez Borges. Cotidiano e sobrevivência: a vida do trabalhador pobre na cidade de São Paulo, 1890-1914.São Paulo: Edusp, 1994.

PONTE, Sebastião Rogério. Fortaleza belle époque: reformas urbanas e controle social (1860-1930). Fortaleza: Fundação Demócrito Rocha/Multgraf Editora, 1993.

RIOS, Kênia Sousa. Isolamento e poder: Fortaleza e os campos de concentração na seca de 1932. Dissertação de Mestrado em História Social. São Paulo: PUC/SP, 1998.

THEOPHILO, Rodolpho. Variola e vacinação no Ceará. - Ed. Fac-sim. Fortaleza: Fundação Waldemar Alcântara, 1997. 